\title{
QUALIDADE DO LEITE PRODUZIDO NO MUNICÍPIO DE RIO POMBA, MG, COM BASE EM ASPECTOS REGULATÓRIOS
}

\author{
Vitor Ibrahim Brandão \\ Tecnólogo em Laticínios/ IF Sudeste MG Campus Rio Pomba / MG \\ vitoribrahimbrandao@hotmail.com
}

\section{Simone Vilela Talma}

Mestre em Produção Vegetal / UENF / RJ

Instituto Federal de Educação, Ciência e Tecnologia de Sergipe Campus Glória / IFS /

SE simonevtalma@yahoo.com.br

\section{Maurílio Lopes Martins}

Doutor em Microbiologia Agrícola / UFV/ MG

Departamento de Ciência e Tecnologia de Alimentos / IF Sudeste MG Campus Rio Pomba / MG

m_lopesm@yahoo.com.br

\section{Aurélia Dornela de Oliveira Martins \\ Doutora em Ciência e Tecnologia de Alimentos/ UFV/MG \\ Departamento de Ciência e Tecnologia de Alimentos / IF Sudeste MG Campus Rio Pomba / MG aureliadom@yahoo.com.br}

\section{Cláudia Lúcia de Oliveira Pinto}

Doutora em em Microbiologia Agrícola / UFV/ MG

Empresa de Pesquisa Agropecuária de Minas Gerais/ Viçosa / MG

claudia.epamig@gmail.com

Recebido: 01 de outubro de 2012. Revisado: 31 de março de 2013. Aceito: 18 de junho de 2013. Publicado online: 17 de julho de 2013.

\section{RESUMO}

Considerando os diversos problemas tecnológicos e econômicos que os microrganismos psicrotróficos ocasionam à indústria de laticínios, o objetivo deste trabalho foi avaliar a qualidade microbiológica do leite cru granelizado da região de Rio Pomba, MG, bem como as condições de manutenção e armazenamento deste produto. Um questionário estruturado foi aplicado a fim de promover o levantamento dos dados dos tanques de expansão comunitários do Município de Rio Pomba, Minas Gerais, e amostras de $200 \mathrm{~mL}$ de leite cru refrigerado foram coletadas e levadas ao Laboratório de Microbiologia para determinação da população de microrganismos mesófilos, psicrotróficos e psicrotróficos proteolíticos. Imprudências foram verificadas durante o processo de recepção e armazenamento do leite cru refrigerado e durante a higienização dos tanques de granelização que possibilitam o acesso de microrganismos ao leite. Desta forma, 54\% e 59\% das amostras, respectivamente, coletadas no período de dezembro de 2008 a fevereiro de 2009 e de abril a maio de 2009, não atenderam a legislação vigente em relação ao número de microrganismos aeróbios mesófilos. Constatou-se que $30 \%$ das amostras de leite cru coletadas no período de abril a maio de 2009 apresentaram acima de $10^{4}$ UFC. $\mathrm{mL}^{-1}$ de microrganismos psicrotróficos proteolíticos. Portanto, os valores de contagem microbiana encontradas neste trabalho sugerem a possibilidade de atividade deterioradora com consequente perda de qualidade do leite cru refrigerado.

Palavras-chave: Leite cru; Tanques de expansão; Microbiota psicrotrófica. 


\begin{abstract}
Considering the many economic and technological problems that psychrotrophic microorganisms promote to the dairy industry, the aim of this work was to evaluate the microbiological quality of bulk raw milk of Rio Pomba area as well as the conditions of maintenance and storage of this product. A questionnaire was applied in order to know the data of all tanks of Rio Pomba area and samples of $200 \mathrm{~mL}$ of cooled raw milk were collected and lead up to the Microbiology Laboratory in order to determine the population of mesophilic, psychrotrophic, and proteolytic psychrotrophic microorganisms. Imprudence was verified during reception and storage of cooled raw milk and during hygiene of tanks that permit the access of microorganisms to milk. Therefore, $54 \%$ and $59 \%$ of samples, respectively, collect in the period of December 2008 to February 2009 and April to May 2009 did not attend the Brazilian legislation in relation to aerobic mesophilic microorganisms. Moreover, it was verified that $30 \%$ of samples of raw milk collected during April to May 2009 presented more than $10^{4} \mathrm{CFU} . \mathrm{mL}^{-1}$ of psychrotrophic proteolytic microorganism. Therefore, the microbiological count values found in this work indicated the possibility of spoilage activity with consequent lost of quality of cooled raw milk.
\end{abstract}

Keywords: Raw milk; Expansion tanks; Psychrotrophic flora.

\title{
1. INTRODUÇÃO
}

O Brasil apresenta expressiva produção de leite, sendo responsável por grande parte do volume total produzido entre os países que compõem o Mercosul, o que coloca o leite entre os seis produtos mais importantes da agropecuária brasileira (CARDOSO, 2006). O país foi o quinto maior produtor de leite do mundo, alcançando 5\% da produção mundial com 31 bilhões de litros de leite em 2011. Esta produção é superior a dos países que mais exportam produtos lácteos para o Brasil, como o Uruguai, que se enquadra na $46^{a}$ posição entre os países de maior produção de leite e a Argentina que se enquadra na $17^{a}$ colocação (EMBRAPA, 2011; IBGE, 2012).

Apesar da significativa importância socioeconômica do setor leiteiro nacional, os indicadores de produtividade da pecuária bovina e, particularmente, da qualidade do leite, evidenciam que esta atividade ainda requer mudanças para alcançar o perfil de negócio efetivamente competitivo e sustentável (BRITO e BRITO, 2004). Assim, a melhoria da qualidade do leite no país tem sido a maior preocupação da indústria de laticínios e das autoridades governamentais ligadas ao setor. A baixa qualidade tem acarretado perdas econômicas e tecnológicas significativas para a indústria e para os produtores (SANTOS e FONSECA, 2003; BARBOSA et al., 2009).

Segundo Chapaval (2000), a qualidade do leite que chega à indústria é consequência da matéria prima que sai da propriedade onde foi produzida. Deste modo, os processadores não podem melhorar a qualidade do leite cru que recebem, mesmo porque, após a pasteurização, o leite demasiadamente contaminado, apresenta enzimas termorresistentes que comprometerão a preservação deste produto, modificando suas características por meio da degradação de proteínas, açúcares e gorduras (DATTA e DEETH, 2001).

Com o intuito de modernizar a legislação sanitária brasileira, a Instrução Normativa ${ }^{\circ} 51$ de 20 de setembro de 2002 (BRASIL, 2002) foi implementada e estabeleceu padrões de identidade e qualidade, conservação, transporte e processamento de leite. Além disso, a fim de padronizar e complementar esta Instrução entrou em vigor a partir de janeiro de 2010, a Instrução Normativa $\mathrm{n}^{\circ} 22$ que estabelece normas técnicas preventivas na utilização de tanques coletivos visando à conservação da qualidade do leite cru, proveniente de diferentes produtores rurais os quais são vinculados aos estabelecimentos de leite e derivados submetidos à inspeção sanitária oficial (BRASIL, 2009).

Entretanto, recentemente, a Instrução Normativa ${ }^{\circ} 62$ de 29 de dezembro de 2011 (BRASIL, 2011) foi implementada a fim de alterar a Instrução Normativa $n^{\circ} 51$ (BRASIL, 2002) e estabelecer padrões de 
qualidade do leite cru mais condizentes com a realidade do país. Assim, foi excluída a classificação do leite em tipo B e C, passando a existir somente leite cru do tipo A e leite cru refrigerado. Esta legislação também passou a preconizar a manutenção do leite cru refrigerado por no máximo 48 horas a $4,0{ }^{\circ} \mathrm{C}$ em tanques de expansão, ou seja, tanques utilizados para armazenamento de leite refrigerado que emprega sistema de refrigeração à gás, nas propriedades, sendo que o leite deve atingir esta temperatura no máximo em 3 horas após o término da ordenha. Também estabeleceu a redução nos limites aceitáveis de microrganismos mesófilos aeróbios (UFC.mL ${ }^{-1}$ ) e células somáticas $\left(C C S . \mathrm{mL}^{-1}\right.$ ) a partir de 01/01/2012 até 30/06/2014 para as regiões Sul, Sudeste e Centro-Oeste para no máximo 6,0 x $10^{5}$ e inclusão da análise de agentes inibidores do crescimento microbiano na lista de análises a serem realizadas em cada boca do caminhão tanque. Esta Instrução determina também a remoção da opção de bombeamento do leite diretamente de latões refrigerados por imersão. Além disso, passou-se a exigir que os caminhões de transporte do leite fossem lavados externamente antes do descarregamento e higienizados internamente após cada descarga.

Com o resfriamento do leite, crescente importância tem sido dada ao grupo dos microrganismos psicrotróficos, pois estes estão frequentemente envolvidos em alteração na composição físico-química do leite. Uma importante característica destes microrganismos é a capacidade de se multiplicar a $7^{\circ} \mathrm{C}$ ou menos, independente de sua temperatura ótima de crescimento (SØRHAUG e STEPANIAK, 1997; JONGHE et al., 2011). Os microrganismos psicrotróficos contribuem para a deterioração do leite e derivados devido à produção de enzimas proteolíticas e lipolíticas que são resistentes aos tratamentos térmicos e são secretadas no leite cru durante a estocagem, antes do processamento (CHEN et al., 2003; MARTINS, 2007; BARBOSA et al. 2008). A atividade remanescente dessas enzimas pode reduzir a qualidade sensorial e a vida de prateleira dos produtos lácteos. Além disso, possíveis contaminações pós-pasteurização por vários tipos de microrganismos, principalmente bactérias do gênero Pseudomonas Migula, 1894 podem ocorrer (WIEDMANN et al., 2000).

As enzimas proteolíticas produzidas por bactérias psicrotróficas podem também resultar em problemas tecnológicos para a indústria de laticínios, como: a instabilidade do leite ao calor, coagulação durante a pasteurização, gelificação do leite UHT, desenvolvimento de sabores e odores indesejáveis e perda de rendimento na produção de queijos (COUSIN, 1982; SØRHAUG e STEPANIAK, 1997; RAYANALLJUTOVAC et al., 2005; BARBOSA et al., 2009).

Além disso, a combinação da manutenção do leite a uma temperatura mais baixa de estocagem e ao seu prolongado tempo de armazenamento possibilita uma seletiva vantagem para as bactérias psicrotróficas, principalmente o grupo das Pseudomonas (DUFOUR et al., 2008; MARCHAND et al., 2009), que colonizam o leite cru por meio da formação de biofilmes residentes nos próprios tanques de estocagem de leite, por água contaminada e por fragmentos de solo (SIMÕES et al., 2009).

Dessa forma, o controle da contaminação do leite por microrganismos psicrotróficos, de seu desenvolvimento, produção e atividade de enzimas deterioradoras é muito importante para a manutenção da qualidade do leite (MARTINS et al., 2005; MARTINS, 2007; JONGHE et al., 2011). Considerando a relevância da contaminação inicial do leite e a multiplicação dos microrganismos psicrotróficos nas temperaturas de refrigeração, objetivou-se, neste trabalho, verificar as condições das instalações dos tanques de granelização coletivos de leite cru refrigerado, as práticas higiênico-sanitárias adotadas para a manutenção da qualidade do leite nos tanques, bem como a qualidade microbiológica do leite cru refrigerado dos tanques de granelização do município de Rio Pomba, MG.

\section{MATERIAL E MÉTODOS}

Este estudo foi realizado no município de Rio Pomba, que possui área de $251,76 \mathrm{~km}^{2}$, localizado na Zona da Mata Mineira (micro-região de Ubá). Constituído por uma população de pequenos e médios proprietários rurais e/ou agroindustriais, cuja estrutura produtiva está alicerçada nas atividades de subsistência que é dependente da produção de leite (CEFET-RP, 2007), com uma expressiva produção deste alimento a partir 2005 (UNIREGISTRO, 2011). 
Os experimentos foram analisados no Departamento de Ciência e Tecnologia de Alimentos do Instituto Federal de Educação, Ciência e Tecnologia do Sudeste de Minas Gerais (IF Sudeste MG), Câmpus Rio Pomba e consistiram de dados avaliados por meio de um questionário aplicado, coletas de amostras de leite e de análise microbiológica.

\subsection{Aplicação de questionário relacionado à adequação dos tanques coletivos à Instrução Normativa ${ }^{\circ}$ 22}

Visitas técnicas foram realizadas no período de junho a agosto de 2010 em 10 propriedades com tanques de expansão coletivo de leite no município de Rio Pomba. Um questionário contendo questões relacionadas ao estabelecido pela Instrução Normativa $n^{\circ} 22$ (BRASIL, 2009) foi aplicado com a finalidade de verificar se os produtores de leite estavam cientes da corresponssabilidade pelo tanque e cumprimento do disposto nesta legislação. O questionário continha as seguintes questões: identificação do entrevistado; característica do titular do tanque comunitário; cadastro do responsável pelo tanque; localização da propriedade rural onde se encontra o tanque comunitário; capacitação do responsável pela recepção e seleção do leite; características e condições do equipamento; verificação e especificação do cômodo de instalação; procedimento de armazenamento do leite no tanque de refrigeração; processo de higienização do tanque e do local de instalação; verificação de registro dos produtores que entregam leite nos tanques coletivos e verificação do procedimento de transporte do leite das propriedades até os tanques coletivos.

Os dados foram catalogados em planilha do excel construindo-se assim um banco de dados que posteriormente foi analisado por meio de análises estatísticas descritivas.

\subsection{Coleta das amostras de leite cru granelizado}

Amostras de $200 \mathrm{~mL}$ de leite cru refrigerado granelizado foram coletadas, assepticamente, em frascos de vidro esterilizados, em todos os 37 tanques de granelização de leite, incluindo tanques individuais e coletivos, do Município de Rio Pomba, no período de dezembro de 2008 a agosto de 2009. Após a coleta, as amostras foram imediatamente, colocadas em banho de gelo, com temperatura inferior a $4{ }^{\circ} \mathrm{C}$, e transportadas ao Laboratório de Microbiologia do Departamento de Ciência e Tecnologia de Alimentos do IF Sudeste MG, Câmpus Rio Pomba para a determinação de bactérias mesofílicas aeróbias, psicrotróficas e psicrotróficas proteolíticas. Além disso, no período de junho a agosto de 2010 também foram coletadas amostras de leite em todos os tanques coletivos do Município, totalizando 10 tanques, para determinação da população de microrganismos psicrotróficos. A temperatura do leite foi medida no momento das coletas.

\subsection{Determinação da população de microrganismos do leite cru granelizado}

A população de microrganismos mesófilos aeróbios foi determinada conforme estabelecido na Instrução Normativa $n^{\circ} 62$ de 26 de agosto de 2003 (BRASIL, 2003). Para isso diluições decimais das amostras de leite cru foram plaqueadas em Ágar Padrão para Contagem (PCA).

A contagem de bactérias psicrotróficas e psicrotróficas proteolíticas foi realizada em ágar leite, com incubação a $6,5 \pm 0,5^{\circ} \mathrm{C}$, por 10 dias (MARTINS, 2007).

\section{RESULTADOS E DISCUSSÃO}

Observou-se que existem imprudências cometidas durante o processo de recepção e armazenamento do leite cru refrigerado e durante a higienização dos tanques comunitários tais como presença de animais nas proximidades do tanque de expansão, ausência de treinamento do responsável pelo tanque, ausência de boas práticas para recebimento e estocagem do leite como higienização adequada dos utensílios utilizados nesta operação, ausência de análise para verificação da qualidade do leite antes de colocá-lo no tanque, utilização de água não tratada para higienização dos tanques, ausência de sanitização do tanque após a limpeza, bem como escolha dos produtos de limpeza e higienização inadequados (Tabela 1). Portanto, tais práticas possibilitam o acesso de microrganismos ao leite que, consequentemente, podem comprometer sua qualidade microbiológica. Assim, durante a estocagem e armazenamento do leite cru refrigerado, bactérias 
psicrotróficas podem acessar o leite, multiplicar sob refrigeração e promover uma série problemas tecnológicos para a indústria de laticínios.

Tabela 1. Quantitativo das respostas obtidas após observação e aplicação de questionário aos responsáveis pelos tanques coletivos de granelização de leite cru no município de Rio Pomba, MG, no período de junho a agosto de 2010

\begin{tabular}{|c|c|}
\hline Respostas dos entrevistados ou verificadas no local & $(\%)$ \\
\hline \multicolumn{2}{|l|}{ Titular do tanque comunitário } \\
\hline São produtores de leite & 100 \\
\hline Adquiriram o tanque pela sua pessoa física & 90 \\
\hline São proprietários do terreno & 100 \\
\hline Têm conhecimento da Instrução Normativa $n^{\circ} .22$ & 20 \\
\hline Sabem da corresponsabilidade pelo tanque & 10 \\
\hline \multicolumn{2}{|l|}{ Responsável pela recepção e seleção do leite } \\
\hline Não foi treinado & 40 \\
\hline Não realiza o teste de alizarol antes de colocar o leite no tanque & 40 \\
\hline Realiza a pesagem ou medição do leite antes de colocá-lo no tanque & 100 \\
\hline Recebe da indústria dados relacionados à chegada do leite na sua plataforma & 20 \\
\hline Recebeu algum treinamento de capacitação da indústria de laticínios & 20 \\
\hline Recebe auditagem no tanque pelo estabelecimento industrial & 60 \\
\hline \multicolumn{2}{|l|}{ Característica da propriedade que contem tanque comunitário } \\
\hline Possui apenas um tanque comunitário & 100 \\
\hline O tanque apresenta visualmente bom estado de conservação & 100 \\
\hline Presença de animais no local de instalação do tanque & 30 \\
\hline \multicolumn{2}{|l|}{ Capacidade do tanque de expansão: } \\
\hline Acima de 2000 litros & 30 \\
\hline De 1000 a 2000 litros & 40 \\
\hline Até 1000 litros & 30 \\
\hline \multicolumn{2}{|l|}{ Volume de leite colocado nos tanques pelos produtores: } \\
\hline Acima de 2000 litros & 0 \\
\hline De 1000 a 2000 litos & 20 \\
\hline Até 1000 litros & 80 \\
\hline \multicolumn{2}{|l|}{ Especificação do local de instalação do tanque } \\
\hline O cômodo possui paredes & 100 \\
\hline Possui cobertura & 100 \\
\hline Possui pavimentação & 10 \\
\hline Possui iluminação & 100 \\
\hline O local é arejado e de fácil acesso & 100 \\
\hline Não possui água tratada e não avalia sua qualidade físico-química e microbiológica & 100 \\
\hline Possui local próprio para higienização dos latões e demais utensílios & 70 \\
\hline Possui local próprio para higienização dos latões, mas não utiliza & 50 \\
\hline \multicolumn{2}{|l|}{ Procedimentos de recepção e armazenamento do leite } \\
\hline O leite é coado antes de ser adicionado ao tanque & 100 \\
\hline Material utilizado pra coar o leite: & \\
\hline Nylon & 40 \\
\hline Aço inoxidável & 30 \\
\hline Peneira & 30 \\
\hline A temperatura do leite é inferior a $4^{\circ} \mathrm{C}$ após três horas de armazenamento & 80 \\
\hline Os latões são higienizados após a entrega do leite com sanitizante específico & 20 \\
\hline $\begin{array}{l}\text { O responsável utiliza o mesmo detergente usado em sua residência para higienizar o } \\
\text { tanque }\end{array}$ & 80 \\
\hline
\end{tabular}
tanque

Procedimento de higienização

Ocorre limpeza após a retirada do leite dos tanques 
O responsável possui e utiliza utensílios apropriados para higienização $\quad 80$

Metodologia empregada para higienização foi estabelecida por conta própria 90

A metodologia consiste de enxágue, aplicação de detergente, remoção com água e

secagem natural

O responsável não anota a frequência de higienização

100

100

Ocorre acumulo de água ao redor do tanque após a lavagem

30

\begin{tabular}{lc}
\multicolumn{1}{c}{ Ocorre acumulo de água ao redor do tanque após a lavagem } & 30 \\
\hline Não possuem cadastro no SIGSIF & 90 \\
São vinculados ao estabelecimento industrial & 100 \\
Não são cadastrados no serviço de defesa estadual & 100 \\
O laticínio não disponibiliza orientações para o cadastro & 100 \\
\hline \multicolumn{2}{c}{ Tranporte do leite para o tanque comunitário } \\
\hline Imediatamente após a ordenha & 30 \\
De 10 a 20 minutos após a ordenha & 50 \\
Até 30 minutos & 20 \\
O transporte do leite da propriedade até o tanque é realizado em latões & 100 \\
O responsável pelo tanque não aceita leite resfriado & 90
\end{tabular}

Constatou-se que na maioria das propriedades avaliadas as temperaturas para a refrigeração do leite apresentava-se inadequada (Figura 1), o que compromete a sua qualidade. Na coleta realizada no período de abril a maio de 2009 e no período de junho a agosto de 2009, observou-se um ligeiro aumento do percentual de tanques de leite cru com temperaturas entre $1{ }^{\circ} \mathrm{C} \mathrm{e} 4{ }^{\circ} \mathrm{C}$ (Figura 1 - B e C), provavelmente devido a menor temperatura ambiente neste período do ano. Segundo Fonseca e Santos (2000), na maioria das propriedades leiteiras do Brasil, a temperatura de refrigeração oscila entre $5^{\circ} \mathrm{C}$ e $10^{\circ} \mathrm{C}$, o que confere, um resfriamento parcial do leite, contribuindo para a multiplicação rápida de microrganismos psicrotróficos.

Na coleta realizada nos tanques comunitários no período de junho a agosto de 2010 (Figura 1 - D), observou-se uma variação da temperatura de $-1,5^{\circ} \mathrm{C}$ a $4,5{ }^{\circ} \mathrm{C}$, o que indicou um bom funcionamento dos tanques neste período. Possivelmente, este resultado se deve ao fato de uma maior conscientização dos produtores após a aplicação do questionário o que fortifica e demostra a importância dos trabalhos de instrução acompanhada de extensão. Porém, o congelamento do leite constatado foi ocasionado devido o volume de leite no tanque ser inferior a $10 \%$ da sua capacidade máxima, não oferecendo condições para que o misturador do tanque tivesse contato com o leite.

Lorenzetti (2006), ao pesquisar a influência do tempo e da temperatura no desenvolvimento de microrganismos psicrotróficos no leite cru de dois tanques da região Sul do Brasil, sugeriu que a refrigeração do leite cru até a chegada na unidade beneficiadora não é suficiente para a manutenção da qualidade microbiológica da matéria prima dependendo do tempo que este leite fica submetido à refrigeração.

(A)

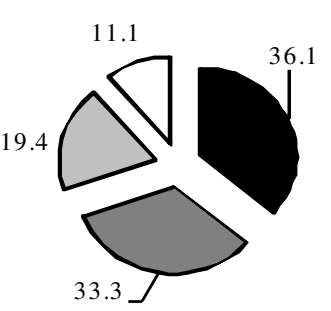

(B)

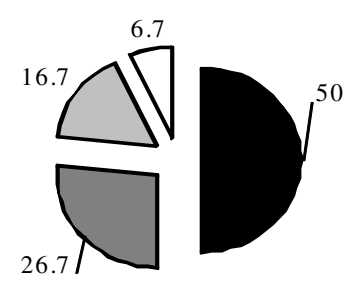

(C)

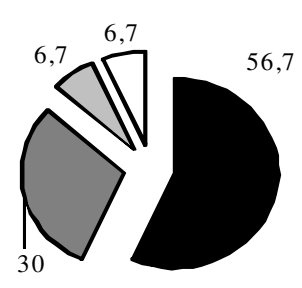

(D)

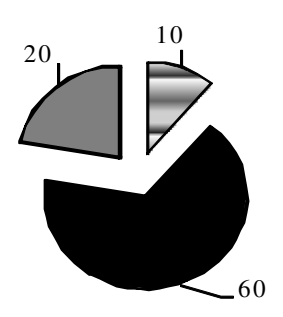

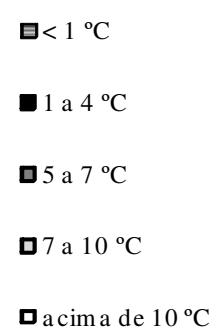

日 $<1{ }^{\circ} \mathrm{C}$

- 1 a $4{ }^{\circ} \mathrm{C}$

D5 a $7{ }^{\circ} \mathrm{C}$

Dacima de $10^{\circ} \mathrm{C}$

Figura 1. Variação de temperatura do leite cru no momento da amostragem. (A): dezembro de 2008 a fevereiro de 2009, (B): abril a maio de 2009, (C): julho a agosto de 2009 e (D) junho a agosto de 2010.

Contagens elevadas de microrganismos mesófilos, psicrotróficos e psicrotróficos proteolíticos foram encontradas nas amostras de leite cru granelizado procedentes dos tanques de expansão do município de Rio Pomba (Tabela 2). Uma vez que as exigências do Ministério da Agricultura, na ocasião das coletas, para as 
regiões Sul, Sudeste e Centro-Oeste permitia em torno de 7,5 x $10^{5}$ UFC. $\mathrm{mL}^{-1}$ de microrganismos mesófilos aeróbios (BRASIL, 2002), 54\% e 59\% do leite amostrado no período de dezembro de 2008 a fevereiro de 2009 e de abril a maio de 2009, respectivamente, não atenderam a legislação. As altas contagens encontradas provavelmente estão relacionadas às falhas cometidas durante o processo de recepção e estocagem do leite cru. Considerando o valor estabelecido igual a $6,0 \times 10^{5} \mathrm{UFC}^{\mathrm{mL}} \mathrm{m}^{-1}$ na Instrução Normativa ${ }^{\circ} 62$ (BRASIL, 2011) para contagem de microrganismos mesófilos aeróbios no leite cru refrigerado, o percentual de amostras em desacordo com este valor seria ainda maior.

A contagem de bactérias psicrotróficas no leite cru refrigerado variou entre 5,0 x $10^{1} \mathrm{UFC} \cdot \mathrm{mL}^{-1}$ a 6,5 x $10^{8}$ UFC. $\mathrm{mL}^{-1}$ (estimado) nas amostras coletadas em tanques individuais e entre $1,0 \times 10^{2}$ UFC.mL $\mathrm{mL}^{-1}$ a 6,5 x $10^{8}$ UFC.mL $\mathrm{mL}^{-1}$ (estimado) nos tanques coletivos, o que indica pouca variação na qualidade microbiológica do leite obtido de tanques individuais e coletivos.

Segundo Coelho (2000), vários fatores podem ocasionar uma baixa qualidade microbiológica do leite, dentre eles a limpeza e sanitização inadequada do equipamento de ordenha e do tanque de resfriamento, a ordenha de animais com úberes e tetos sujos, a falta de resfriamento ou o resfriamento insatisfatório dos tanques de expansão individuais e coletivos do leite, bem como leite com altas contagens bacterianas proveniente de vacas com mastite. A manutenção do leite cru refrigerado por períodos maiores, como três a quatro dias antes de ser processado, pode assegurar tempo suficiente para a multiplicação de microrganismos como Pseudomonas fluorescens Migula, 1895 e outros psicrotróficos que podem alcançar populações de $10^{4}$ a $10^{6}$ UFC.mL ${ }^{-1}$ (KOHLANN et al., 1991; MARTINS, 2007).

Tabela 2. Percentual de microrganismos mesófilos aeróbios, psicrotróficos e psicrotróficos proteolíticos de amostras de leite dos tanques individuais e coletivos coletadas no município de Rio Pomba, MG, no período de dezembro de 2008 a agosto de 2010

\begin{tabular}{|c|c|c|c|c|c|c|c|}
\hline \multirow[t]{2}{*}{$\begin{array}{l}\text { Período de } \\
\text { análise }\end{array}$} & \multicolumn{2}{|c|}{$\begin{array}{c}\text { Mesófilos aeróbios } \\
\left(\log \text { UFC.mL } L^{-1}\right)\end{array}$} & \multicolumn{3}{|c|}{$\begin{array}{l}\text { Psicrótroficos } \\
\left(\log \text { UFC.mL } L^{-1}\right)\end{array}$} & \multicolumn{2}{|c|}{$\begin{array}{l}\text { Psicrotróficos proteolíticos } \\
\qquad\left(\log \text { UFC.mL }{ }^{-1}\right)\end{array}$} \\
\hline & $<5,9$ & $>5,9$ & $<4,0$ & $>4,0$ e $<6,0$ & $>6,0$ & $<4,0$ & $>4,0$ \\
\hline $\begin{array}{l}\text { Dezembro de } \\
2008 \text { a fevereiro } \\
\text { de } 2009\end{array}$ & $46 \%$ & $54 \%$ & $37 \%$ & $46 \%$ & $17 \%$ & $30 \%$ & $70 \%$ \\
\hline $\begin{array}{l}\text { Abril a maio de } \\
2009\end{array}$ & $41 \%$ & $59 \%$ & $14 \%$ & $40 \%$ & $46 \%$ & $70 \%$ & $30 \%$ \\
\hline $\begin{array}{l}\text { Junho a agosto de } \\
2010\end{array}$ & ND & ND & $10 \% *$ & $70 \% *$ & $20 \% *$ & ND & ND \\
\hline
\end{tabular}

(ND): não determinado; $(*)$ : amostras procedentes somente dos tanques comunitários. Faixa estabelecida pelo Ministério da Agricultura, Pecuária e Abasteciemento (BRASIL, 2011) para micorganismos mesófilos aeróbios $\left(<6,0\right.$ x $10^{5}$ UFC. $\mathrm{mL}^{-1}$ ou $\left.<5,8 \log \mathrm{UFC} . \mathrm{mL}^{-1}\right)$.

Proteases têm sido detectadas em leite com essa população de psicrotróficos (COUSIN, 1982). Entretanto, a contaminação elevada por psicrotróficos não indica a presença de enzimas microbianas associadas à perda de qualidade e redução de vida útil dos produtos lácteos. A presença de uma contaminação baixa por psicrotróficos também não é uma garantia de qualidade do leite.

Conforme demonstrado na Tabela 2, muitas amostras de leite cru apresentaram acima de $10^{4}$ UFC. $\mathrm{mL}^{-1}$ de microrganismos psicrotróficos proteolíticos. Adams et al. (1975) detectaram proteases termorresistentes com valor $\mathrm{D}$, tempo necessário a uma dada temperatura para reduzir $90 \%$ da atividade enzimática, a $149{ }^{\circ} \mathrm{C}$ de 90 segundos em amostras de leite estocadas a $4{ }^{\circ} \mathrm{C}$ e, nessas amostras, a contagem padrão de psicrotróficos variou de $10^{3}$ a $10^{4}$ UFC $\mathrm{mL}^{-1}$. Portanto, os valores de contagem padrão de microrganismos psicrotróficos proteolíticos encontrados neste trabalho sugerem a possibilidade de atividade

Persp. online: biol. \& saúde, Campos dos Goytacazes, 9 (3), 46-55, 2013

seer.perspectivasonline.com.br 
deterioradora destes microrganismos com consequente perda de qualidade do leite cru refrigerado.

Entretanto, este trabalho limitou-se em estudar a qualidade do leite somente no município de Rio Pomba, MG, e a identificação dos microrganismos psicotróficos não foi alvo da pesquisa, como em outros trabalhos conduzidos por Martins et al. (2005); Rasolofo et al. (2010); Jonghe et al. (2011) e Raats et al. (2011) que isolaram e identificaram bactérias deterioradoras, tais como as do gênero Pseudomonas e patogênicas como Aeromonas hydrophila (Chester, 1901) Stanier 1943, Listeria monocytogenes (Murray et al., 1926) Pirie 1940, dentre outras no leite cru refrigerado.

\section{CONCLUSÕES}

A contaminação elevada constatada nas amostras de leite cru refrigerado pode estar associada com procedimentos de higienização inadequados no sistema de produção, nos tanques de granelização de leite cru, no armazenamento e no transporte, uma vez que, resíduos remanescentes de leite presentes na superfície dos equipamentos constituem meio de cultura rico em nutrientes para o crescimento de bactérias, as quais contaminam o produto em etapas subsequentes. Assim, a utilização de tanques de expansão individuais e coletivos nas propriedades rurais não é suficiente para a obtenção de leite cru de boa qualidade microbiológica, sendo de grande importância o desenvolvimento de programas de assistência aos produtores de leite para assegurar a manutenção da qualidade microbiológica do leite cru.

\section{REFERÊNCIAS BIBLIOGRÁFICAS}

ADAMS B. M.; BARACH, J. T.; SPECK, M. L. Heat resistant proteases produced in milk by psychrotrophic bacteria of dairy origin. Journal of Dairy Science, v. 58, n. 6, p. 828-835, 1975.

BARBOSA, J. B.; BATISTA, C. S.; VANETTI, M. C. D.; PINTO, C. L. O.; MARTINS, M. L. Perda de rendimento na produção de queijos minas frescal e minas padrão fabricados a partir de leite contaminado com Pseudomonas fluorescens. In: ANAIS DO XXV CONGRESSO NACIONAL DE LATICÍNIOS, 2008, Juiz de Fora. Resumos... Juiz de Fora: EPAMIG, 2008. p. 1-8.

BARBOSA, J. B.; TALMA, S. V.; BATISTA, C. S.; MARTINS, M. L.; PINTO , C. L. O. Avaliação de rendimento da produção dos queijos minas frescal, minas padrão e mussarela fabricados com leite inoculado com Pseudomonas fluorescens. Revista do Instituto de Laticínios Cândido Tostes, v. 64, n. 371, p. 26-33, 2009.

BRASIL. Ministério da Agricultura, Pecuária e Abastecimento. Departamento de Inspeção de Produtos de origem Animal. Instrução Normativa ${ }^{\circ} 51$, de 18 de setembro de 2002. Aprova os Regulamentos Técnicos de Produção, Identidade e Qualidade do Leite tipo A, do Leite tipo B, do Leite tipo C, do Leite Pasteurizado e do Leite Cru Refrigerado e o Regulamento Técnico da Coleta de Leite Cru Refrigerado e seu Transporte a Granel. Diário Oficial da República Federativa do Brasil. Brasília, 20 set. 2002, Seção I, p.13.

BRASIL. Ministério da Agricultura, Pecuária e Abastecimento. Departamento de Inspeção de Produtos de Origem Animal. Instrução Normativa n. ${ }^{\circ} 62$, de 26 de agosto de 2003. Métodos analíticos oficiais para análises microbiológicas para controle de produtos de origem animal e água. Diário Oficial da República Federativa do Brasil, Brasília, DF, 18 set., 2003.

BRASIL. Ministério da Agricultura, Pecuária e Abastecimento. Departamento de Inspeção de Produtos de Origem Animal. Instrução Normativa n. ${ }^{\circ} 22$, de 07 de julho de 2009. Estabelece as normas técnicas para utilização de tanques comunitários visando conservação da qualidade do leite cru, proveniente de diferentes propriedades rurais. Diário Oficial da República Federativa do Brasil, Brasília, DF, 08 jul., 2009.

BRASIL. Ministério da Agricultura, Pecuária e Abastecimento. Departamento de Inspeção de Produtos de origem Animal. Instrução Normativa $\mathrm{n}^{\circ} 62$, de 29 de dezembro de 2011. Aprova o Regulamento Técnico de Produção, Identidade e Qualidade do Leite tipo A, o Regulamento Técnico de Identidade e Qualidade de Leite Cru Refrigerado, Leite Pasteurizado e o Regulamento Técnico da Coleta de Leite Cru Refrigerado e seu Transporte a Granel. Diário Oficial da República Federativa do Brasil. Brasília, 30 dez. 2011.

BRITO, J. R. F.; BRITO, M. A. V. P. Qualidade do leite brasileiro e os desafios para atendimento das exigências internacionais. In: ZOCCAL, et al. Leite: uma cadeia produtiva em transformação. Juiz de Fora: Embrapa Gado de Leite, 2004, p.235-243. 
CARDOSO, R. R. Influência da microbiota psicrotrófica no rendimento de queijo minas frescal elaborado com leite estocado sob refrigeração. 2006. 43f. Dissertação (Mestrado em Microbiologia Agrícola) - Universidade Federal de Viçosa, Viçosa - MG, 2006.

CEFET-RP. CENTRO FEDERAL DE EDUCAÇÃO TECNOLÓGICA DE RIO POMBA. Plano de Desenvolvimento Institucional. Rio Pomba: CEFET-RP, 2007.

CHAPAVAL, L. Leite de qualidade: manejo reprodutivo, nutricional e sanitário. Viçosa: Editora Aprenda Fácil, 2000. 196p.

CHEN, L.; DANIEL, R. M.; COOLBEAR, T. Detection and impact of protease and lipase activities in milk and milk powders. International Dairy Journal, v. 13, p. 255-275, 2003.

CHESTER, F. D. A. Manual of Determinative Bacteriology, New York: The MacMillan Co., 1901, pp. 1401.

COELHO, V. R. P. Programa Nacional da Melhoria da Qualidade do Leite. Monografia. São Paulo: FZEA-USP, 2000.

COUSIN, M. A. Presence and activity of psychrotrophic microorganisms in milk and dairy products: a review. Journal of Food Protection, v. 45, p. 172-207, 1982.

DATTA, N.; DEETH, H. C. Age gelation of UHT-milk - a review. Food Bioproducts Processing, v. 79, p. 197-210, 2001.

DUFOUR, D.; NICODÈME, M.; PERRIN, C.; DRIOU, A.; BRUSSEAUX, E.; HUMBERT, G.; GAILLARD, J.; DARY, A. Molecular typing of industrial strains of Pseudomonas spp. isolated from milk and genetical and biochemical characterization of an extracellular protease produced by one of them. International Journal of Food Microbiology, v. 125, p. 188-196, 2008.

EMBRAPA. Pesquisa trimestral do leite - Leite inspecionado no Brasil. Embrapa Gado de leite, Junho/2011. Disponível em: http://www.cnpgl.embrapa.br/. Último acesso: Agosto de 2012.

FONSECA, L. F. L.; SANTOS, M. V. Qualidade do leite e controle de mastite. Lemos Editora, 2000. 175 p.

IBGE - Instituto Brasileiro de Geografia e Estatística. Pesquisa Pecuária Municipal, 2012. Disponível em: http://www.milkpoint.com.br/estatisticas/ProducaoEstado.htm. Último acesso: Janeiro de 2013.

JONGHE, V.; COOREVITS, A.; HOORDE, K. V.; MESSENS, W.; LANDSCHOOT, A. V.; VOS, P.; HEYNDRICKX, M. Influence of Storage Conditions on the Growth of Pseudomonas Species in Refrigerated Raw Milk. Applied and Environmental Microbiology, v. 77, n. 2, p. 460-470, 2011.

KOHLANN, K. L.; NIELSEN, S. S.; STEENSON, L. R.; LADISCH, M. R. Production of proteases by psychrotrophic microorganism. Journal of Dairy Science, v. 74, p. 3275-32831, 1991.

LORENZETTI, D. K. Influência do tempo e da temperatura no desenvolvimento de microrganismos psicrotróficos no leite cru de dois estados da Região Sul. 2006. 71f. Dissertação (Mestrado em Tecnologia de Alimentos) - Universidade Federal do Paraná. Curitiba - PR, 2006.

MARCHAND, S.; VANDRIESCHE, G.; COOREVITS, A.; COUDIJZER, K.; JONGHE, V.; DEWETTINCK, K.; De VOS, P.; DEVREESE, B.; HEYNDRICKX, M.; BLOCK, J. Heterogeneity of heatresistant proteases from milk Pseudomonas species. International Journal of Food Microbiology, v. 133, p. 68-77, 2009.

MARTinS, M. L.; ARAÚJO, E. F.; MANTOVANI, H. C.; MORAES, C. A.; VANETTI, M. C. D. Detection of the apr gene in proteolytic psychrotrophic bacteria isolated from refrigerated raw milk. International Journal of Food Microbiology, v. 102, p. 203-211, 2005.

MARTINS, M. L. Caracterização de protease e lipase de Pseudomonas fluorescens e quorum sensing em bactérias psicrotróficas isoladas de leite. 2007. 163f. Tese (Doutorado em Microbiologia Agrícola) Universidade Federal de Viçosa. Viçosa - MG, 2007.

MIGULA, W. Über ein neues System der Bakterien. Arbeiten aus dem Bakteriologischen Institut der Technischen Hochschule zu Karlsruhe, v. 1, p. 235-238, 1894. 
MIGULA, W. Bacteriaceae (Stabchenbacterien). In: A. ENGLER and K. PRANTL (ed.): Die Naturlichen Pfanzenfamilien, W. Engelmann, Leipzig, Teil I, Abteilung Ia, 1895, pp. 20-30.

MURRAY, E. G. D.; WEBB, A. A.; SWANN, M. B. R. A disease of rabbits characterized by a large mononuclear leucocytosis caused by a hitherto underscribed bacillus Bacterium monocytogenes $\mathrm{n}$. $\mathrm{sp}$. Journal of Pathology and Bacteriology, v. 29, p. 407-439, 1926.

RAATS, D.; OFFEK, M.; MINZ, D.; HALPERN, M. Molecular analysis of bacterial communities in raw cow milk and the impact of refrigeration on its structure and dynamics. Food Microbiology, v. 28, p. 465471, 2011.

RASOLOFO, E. A.; ST-GELAIS, D.; LAPOINTE, G.; ROY, D. Molecular analysis of bacterial population structure and dynamics during cold storage of untreated and treated milk. International Journal of Food Microbiology, v. 138, p. 108-118, 2010.

RAYANAL-LJUTOVAC, K.; GABORIT, P.; LAURET, A. The relationship betweent criteria of goat milk, its technological proprieties and the quality of teh final products. Small Ruminat research, 2005.

SANTOS, M. V.; FONSECA, L. F. L. Bactérias psicrotróficas e a qualidade do leite. Revista CBQL, v. 19, p. 12-15, 2003.

SIMÕES, M.; SIMÕES, L. C.; Vieira, M. J. Species association increases biofilm resistance to chemical and mechanical treatments. Water Research, v. 43, p. 229-237, 2009.

SØRHAUG, T., STEPANIAK, L. Psychrotrophs and their enzymes in milk and dairy products: Quality aspects. Trends in Food Science and Technology, v. 8, p. 35-40, 1997.

UNIREGISTRO. Cidades. Disponível em http://www.uniregistro.com.br/cidades-dobrasil/minasgerais/riopomba/, acessado em 15 de outubro de 2011.

WIEDMANN, M.; WEILMEIER, D.; DINEEN, S. S.; RALYEA, R.; BOOR, J. K. Molecular and phenotypic characterization of Pseudomonas spp. isolated from milk. Applied and Environmental Microbiology, v. 66, p. 2085-2095, 2000. 